\title{
Clinical Study of Perforation Peritonitis- A Study of 100 Cases
}

\author{
Dr.SudershanKapoor ${ }^{1}$, Dr.SudhirKhichy, Dr.Sahil Mittal. \\ ${ }^{1}$ Professor, ${ }^{2}$ Professor,${ }^{3}$, Resident \\ Department Of Surgery, Govt.MedicalCollege,Amritsar.
}

\begin{abstract}
For the gastrointestinal surgeon, the clinically most relevant form of peritonitis is secondary bacterial peritonitis that is peritoneal inflammation caused by loss of integrity of the gastrointestinal tract with consequent leakage of the intestinal contents into the peritoneal cavity. Despite advances in surgical techniques, antimicrobial therapy and intensive care support, management of peritonitis continues to be highly demanding, difficult and complex. This article attempts to study the etiology, clinical profile, aids to diagnosis and management of perforation peritonitis including management of complications encountered after surgery.

Keywords: clinical study; intestinal perforation; peritonitis; appendix,Peptic perforation
\end{abstract}

\section{Introduction}

Peritonitis is defined as inflammation of the peritoneal cavity.Perforation peritonitis is the most common surgical emergency in India. The spectrum of aetiologyofperforation in India continues to be different from western countries and there is paucity of data regarding its aetiology, prognostic indicators, morbidity and mortality pattern. In majority of cases, presentation to the hospital is late with well-established generalized peritonitis with purulent/faecal contamination and varying degree of septicaemia. ${ }^{1,2}$

Etiology: Typhoid fever is the commonest cause of ileal perforation in India. Other causes of perforation include perforation of peptic ulcers which are usually encountered along the first part of the duodenum anteriorly and in the pylorus of the stomach, nonspecific ileal perforations caused due to sub mucus vascular embolism, chronic ischemia due to atheromatous vascular disease, ischemia due to arteritis or drugs such as enteric coated potassium tablets. These 'nonspecific' ileal perforations are closely followed by small bowel perforations occurring in intestinal tuberculosis. Most of these (50-80\%) occur in the ileum, usually proximal to strictures of the bowel. Other rare causes of perforation include blunt trauma abdomen, intestinal amoebiasis, gastrointestinal carcinomas, foreign bodies, ulcerative colitis, Meckel's diverticulum, steroid ulcer of ileum, radiation treatment for GI malignancy causing mucosal ischemia, iatrogenic perforation.

Other sites of perforation which cause secondary bacterial peritonitis include appendicular perforation secondary to appendicitis, gall bladder perforation secondary to gall stones, perforation due to obstruction, perforation arising from biliary tree, uterus, splenic and liver abscesses.

Patients with perforation peritonitis should be treated with antibiotics, i.v. fluids, electrolyte replacement and blood transfusion. The surgical treatment of perforation peritonitis is based on three basic principles viz: (1) To eliminate the source of bacterial contamination by treating the underlying pathologic process. (2) To decrease the degree of bacterial contamination in the peritoneal cavity. (3) To prevent recurrent or residual infection. ${ }^{1,3}$

Emergency laparotomy is performed to either repair or resect and anastomose the perforated segment or exteriorize the bowel segment bearing the perforation.

An exploratory laparotomy is associated with many complications that arise in the postoperative period. These complications are divided into:

- Immediate complications

- Late complications

Immediate complications include pain, fever, paralytic ileus, abscess (superficial or deep), wound infection/dehiscence, entero-cutaneous fistula.

Late complications include adhesive intestinal obstruction and incisional hernia.

A retrospective study was conducted which involved analysis of 192 patients treated for non-traumatic perforation of small intestine in a tertiary care teaching hospital in North India. The clinical profile and management of the patients were studied. The most common cause of non- traumatic perforation of small intestine was typhoid (46.4\%);followed by non-specific inflammation (39.2\%), tuberculosis (12.8\%o), andmalignant neoplasm (1.6\%).Primary repair was the most frequent procedure (44.0\%), followed by ileostomy $(25.5 \%)$, and resection- anastomosis $(19.3 \%)$. Superficial wound infection was the most frequent post-operative complication $(46.8 \%)$, followed by wound dehiscence $(31.3 \%)$. The wound infection rate was reduced significantly following delayed primary closure of skin incision. Entero-cutaneous fistula/leak developed in 
$11.5 \%$ patients. Salvage ileostomy for post-operative intestinal leak resulted in a better survival rate as compared to conservative treatment ( $85.7 \%$ vs. $50.0 \%)$. The overall mortality rate was $16.6 \%{ }^{4}$

Prajakt V Patil et al studied 150 cases of perforation peritonitis admitted in Dr. R.N.Cooper Municipal General Hospital, Mumbai in the year of 2006. All cases were diagnosed with perforation peritonitis. In the study, 126 patients were male, with male: female ratio of 5.25:1. The mean age was 42.5 years. Majority of patients were from the age group of 21-30 years. Mean hospital stay was of 13 days. The most common suspected etiology was duodenal perforation in $41 \%$ patients. The commonest cause was peptic ulcer perforation with $1^{\text {st }}$ part of duodenum being the commonest site. USG revealed free fluid in $60 \%$, dilated bowel loops in $20 \%$, perforated appendix in $3 \%$ of patients. Commonest site of perforation was duodenum in 70 patients, out of which $1^{\text {st }}$ part was involved in $98 \%$, followed by ileum in $40(26 \%)$, stomach in $15 \%$ patients, appendix $(5$ patients), meckel's diverticulum (5 patients), fallopian tube( 5 patients) and large bowel (2 patients) were the other sites. Overall mortality was $13 \%$ (20 patients). Duodenal perforation carried the maximum mortality (15 patients). The commonest complications were wound infection (20\%), burst abdomen (20\%), ARDS (10\%) and pneumonia $(10 \%)$. In cases of extensive contamination fecal fistula and anastomotic leak were seen. Commonest time interval for occurrence of complication was 10-15 days seen in 60 patients. ${ }^{5}$

\section{Material And Methods}

The study was conducted after approval from institutional thesis and ethical committee and informed consent of the patient was taken.

\section{Sources of data:}

All patients were admitted to the surgery wards at Guru Nanak Dev Hospital, attached to Govt. Medical College, Amritsar, with signs and symptoms of perforation peritonitis.

\section{Method of data collection:}

This is a prospective study in which patients presenting with clinical suspicion of perforation peritonitis in the department of surgery,Guru Nanak Dev Hospital/ Govt. Medical College, Amritsar, were taken into study. - 100 cases were taken up for study and patients were subjected to detailed history and thorough physicalexamination.

- Patients underwent necessary investigations.

- Blood counts, biochemical analysis and urine analysis.

- USG abdomen/pelvis CT-abdomen (as and when required)

- All diagnosed patients were subjected to surgery.

- In all cases, operative findings and postoperative course was followed up for three months for any complication or any need of re-surgery.

- Final outcome was evaluated on the basis of clinical, operative and radiological findings.

\section{Inclusion criteria:}

- All cases of perforation peritonitis irrespective of age and sex

- All cases of perforation peritonitis due to any etiological factor.

- All cases of perforation peritonitis admitted in various wards in Guru Nanak Dev Hospital, Amritsar.

\section{Exclusion criteria:}

Any case of perforation peritonitis due to penetrating trauma.

III. Results

Table 1: Showing Site Of Perforation

\begin{tabular}{|l|l|l|}
\hline SITE & NO. OF CASES & \%AGE \\
\hline Stomach & 20 & 20.00 \\
\hline Duodenum & 7 & 7.00 \\
\hline Jejunum & 2 & 2.00 \\
\hline Terminal ileum & 55 & 55.00 \\
\hline Caecum & 5 & 5.00 \\
\hline Appendix & 8 & 8.00 \\
\hline Meckel's diverticulum & 1 & 1.00 \\
\hline Not identified & 2 & 2.00 \\
\hline Total & 100 & 100.0 \\
\hline
\end{tabular}

Table 1 shows the most common anatomical site for perforation was terminal ileum $(55 \%)$ the next common site was stomach (20\%), followed by appendix (8\%), duodenum (7\%), caecum $(5 \%)$, jejunum (2\%) and Meckel's diverticulum (1\%). In 2\% cases site was not identified due to severe adhesions between gut loops. 


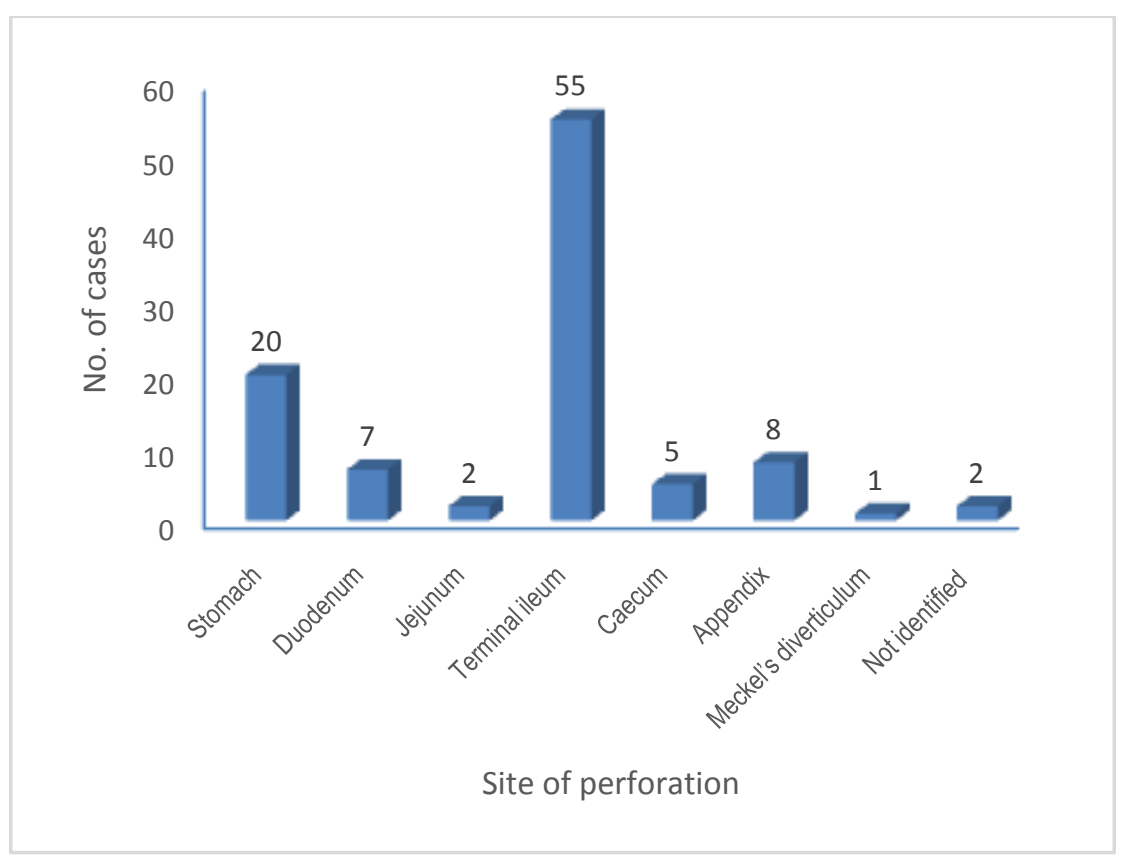

Table 2Showing Etiological Analysis

\begin{tabular}{|l|l|l|}
\hline Etiology & No. Of Cases & \% Age \\
\hline Enteric Fever & 42 & 42.0 \\
\hline Peptic Ulcer (Gastroduodenal) & 27 & 27.0 \\
\hline Traumatic & 3 & 3.0 \\
\hline Tubercular & 15 & 15.0 \\
\hline Appendicular & 8 & 8.0 \\
\hline Meckel's Diverticulum & 1 & 1.0 \\
\hline Intestinal Obstruction & 4 & 4.0 \\
\hline Total & 100 & 100.0 \\
\hline
\end{tabular}

Table 2 shows the most common aetiology of perforation peritonitis was Enteric fever (42\%) followed by peptic ulcer perforations $(27 \%)$, tubercular perforations $(15 \%)$, appendicular perforations $(8 \%)$, intestinal obstruction (4\%), traumatic perforations $(3 \%)$ and meckel's diverticular perforation (1\%).

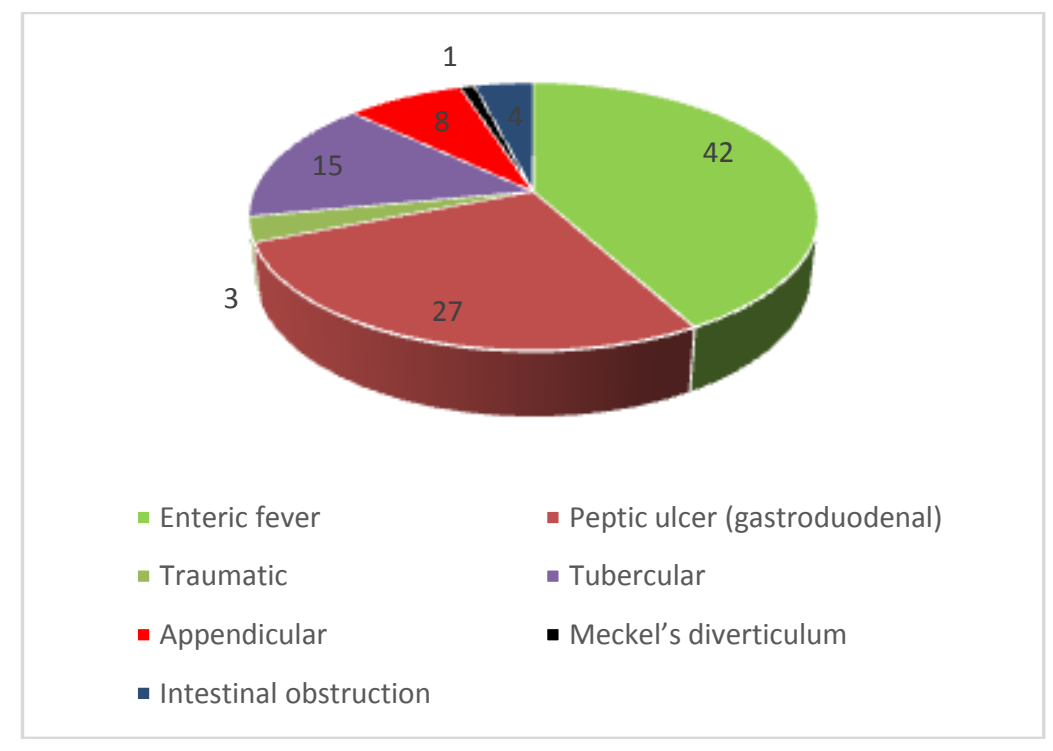

Table 3Showing Type Of Surgical Procedure

\begin{tabular}{|l|l|l|l|l|l|}
\hline Etiology & Suturing & $\begin{array}{l}\text { Omental } \\
\text { patching }\end{array}$ & $\begin{array}{l}\text { Resection } \\
\text { and } \\
\text { anastomosis }\end{array}$ & Appendicectomy & Ileostomy \\
\hline
\end{tabular}




\begin{tabular}{|l|l|l|l|l|l|}
\hline Enteric fever & 30 & 0 & 3 & 0 & 9 \\
\hline Peptic ulcer & 0 & 27 & 0 & 0 & 0 \\
\hline Traumatic & 2 & 0 & 1 & 0 & 0 \\
\hline Tubercular & 3 & 0 & 6 & 0 & 6 \\
\hline Appendicular & 0 & 0 & 1 & 7 & 0 \\
\hline $\begin{array}{l}\text { Meckel's } \\
\text { diverticulum }\end{array}$ & 0 & 0 & 1 & 0 & 0 \\
\hline Obstruction & 0 & 0 & 2 & 0 & 2 \\
\hline Total & 35 & 27 & 14 & 7 & 17 \\
\hline
\end{tabular}

Table 3 shows suturing of the perforation was the most common surgical procedure done in $35 \%$ of the cases, followed by omental patching in $27 \%$ of the cases, followed by ileostomy in $17 \%$ of the cases. Resection and anastomosis was done in $14 \%$ of cases followed by appendicectomy in $7 \%$ of the cases.
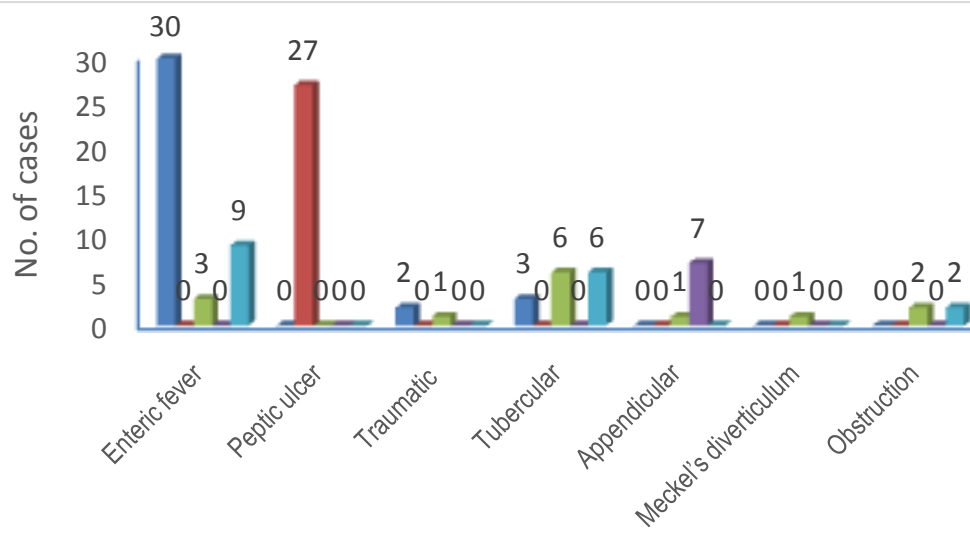

Etiology

- $\quad$ Suturing Omental patching

Resection and anastomosis Appendicectomy

- lleostomy

Table 4Showing Postoperative Complications

\begin{tabular}{|l|c|c|}
\hline Complications & No. of cases & \%age \\
\hline Pain & 100 & 100.0 \\
\hline Fever & 94 & 94.0 \\
\hline Paralytic ileus (>2 days) & 85 & 85.0 \\
\hline Wound infection/ dehiscence & 70 & 70.0 \\
\hline Abscess (superficial/deep) & 5 & 5.0 \\
\hline Anastomotic leak & 8 & 15.0 \\
\hline Burst abdomen & 12 & 12.0 \\
\hline Chest infection & 25 & 25.0 \\
\hline Anemia / hypoproteinemia & 30 & 30.0 \\
\hline Intestinal Obstruction & 04 & 4.0 \\
\hline Incisional hernia & 02 & 2.0 \\
\hline
\end{tabular}

Table 4 shows pain was the most common postoperative complication which was present in $100 \%$ of cases followed by fever which was the 2 nd most common early postoperative complication (94\%). The next common early postoperative complication was paralytic ileus $(85 \%)$ and superficial wound infection was present in $70 \%$ cases. Other postoperative complications were anemia/hypoproteinemia (30\%), chest infection $(25 \%)$, burst abdomen (12\%) and anastomotic leak $(8 \%)$, abscess in $5 \%$ of cases. 4 cases of intestinal obstruction (4\%) and 2 cases of incisional hernia (2\%)were encountered during the follow up period of 3 months. 


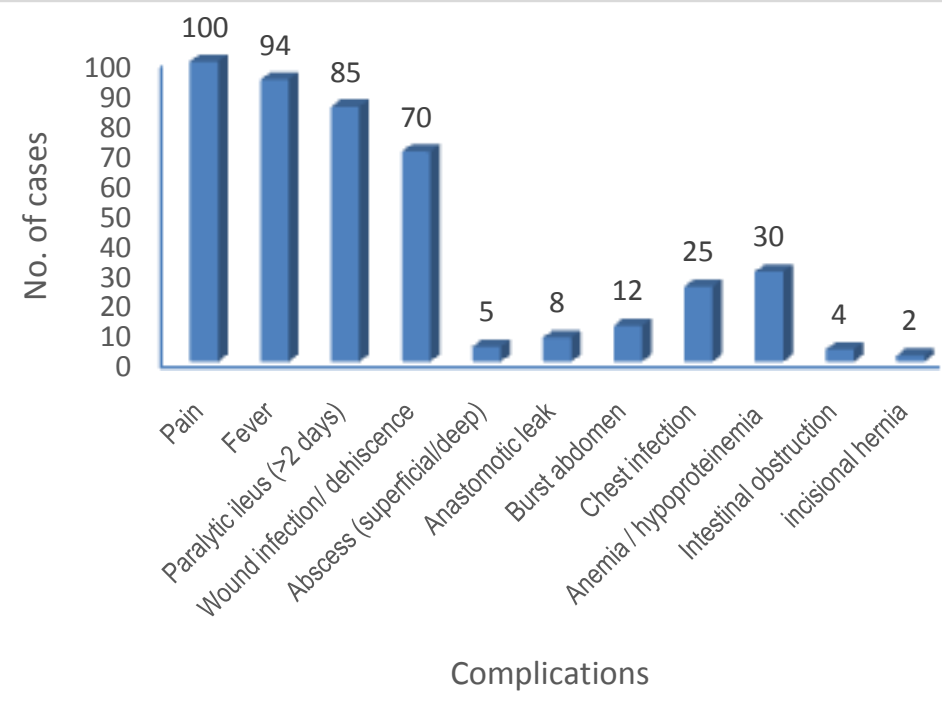

Table 5Management Of Complications In Follow Up Period Of 3 Months

\begin{tabular}{|c|c|c|c|c|c|}
\hline \multirow[t]{2}{*}{ Complication } & \multicolumn{5}{|c|}{ Resurgery done } \\
\hline & Resuturing & $\begin{array}{l}\text { Ileostomy } \\
\text { closure }\end{array}$ & $\begin{array}{l}\text { Resection } \\
\text { and } \\
\text { anastomosis }\end{array}$ & $\begin{array}{l}\text { Exploratory } \\
\text { laparotomy } \\
\text { with } \\
\text { Adhesiolysis }\end{array}$ & $\begin{array}{l}\text { Mesh } \\
\text { repair }\end{array}$ \\
\hline $\begin{array}{l}\text { Wound dehiscence ( } 35 \\
\text { cases) }\end{array}$ & 15 & & & & \\
\hline $\begin{array}{lll}\begin{array}{l}\text { Burst } \\
\text { cases })\end{array} & \text { abdomen } & (12 \\
\end{array}$ & 12 & - & - & - & - \\
\hline Ileostomy (17 cases) & - & 13 & - & - & - \\
\hline $\begin{array}{l}\begin{array}{l}\text { Anastomotic leak } \\
\text { cases) }\end{array} \\
\end{array}$ & - & - & 2 & - & - \\
\hline Obstruction (4 cases) & - & - & - & 2 & - \\
\hline $\begin{array}{lll}\begin{array}{l}\text { Incisional hernia } \\
\text { cases })\end{array} & (2 \\
\end{array}$ & - & - & - & - & 2 \\
\hline
\end{tabular}

Table 5 shows management of complications in the follow up period of 3 months. Out of 35 cases of wound dehiscence 15 cases $(42.86 \%)$ required resuturing of the wound, rest of the cases were treated by local wound management. 12 out of 12 cases $(100 \%)$ of burst abdomen were managed by resuturing. Ileostomy closure was done in 13 out of 17 cases (76.5\%). 4 cases $(23.5 \%)$ died postoperatively. Out of 8 cases of anastomotic leak 2 cases (25\%) had to go for resection and anastomosis, rest were managed conservatively. Out of 4 cases of obstruction, 2 cases $(50 \%)$ had to undergo exploratory laparotomy with adhesiolysis, rest 2 cases were managed conservatively. 2 out of 2 cases (100\%) of incisional hernia were managed by mesh repair of the defect.

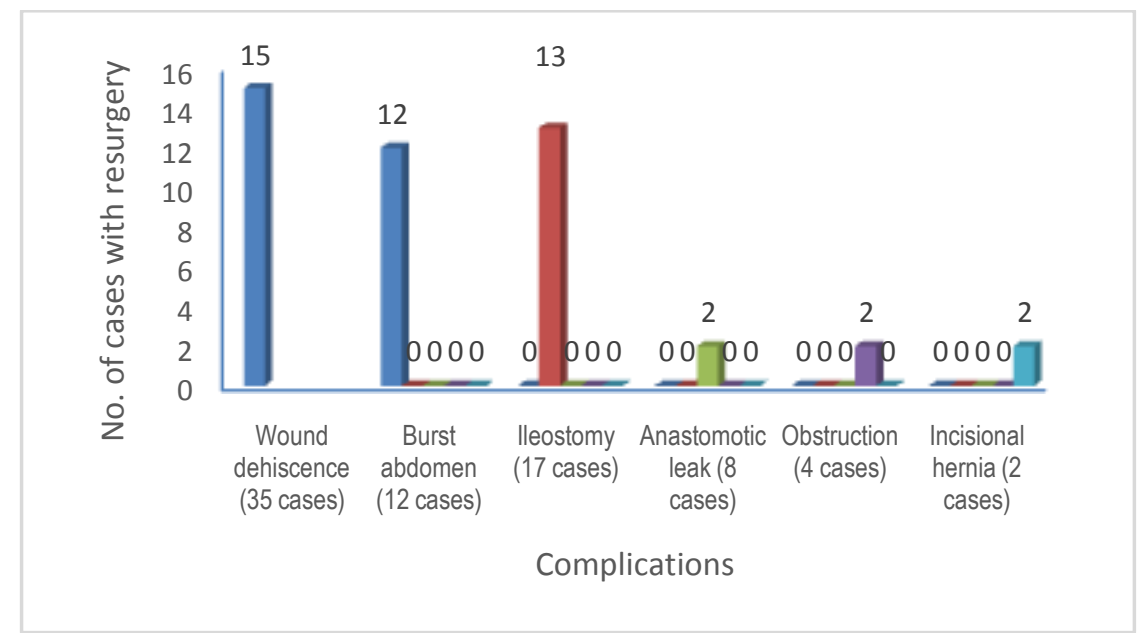

Table 6 


\begin{tabular}{|c|c|c|c|}
\hline \multicolumn{4}{|c|}{ Showing Mortality } \\
\hline Etiology & Cured & Expired & Mortality \%age \\
\hline Enteric fever $(n=42)$ & 39 & 3 & 7.14 \\
\hline Peptic ulcer $(n=27)$ & 27 & 0 & 0 \\
\hline Traumatic $(n=3)$ & 3 & 0 & 0 \\
\hline Tubercular $(\mathrm{n}=15)$ & 8 & 7 & 46.6 \\
\hline Appendicular $(\mathrm{n}=8)$ & 8 & 0 & 0 \\
\hline Meckel's diverticulum $(n=1)$ & 1 & 0 & 0 \\
\hline Obstruction $(n=4)$ & 4 & 0 & 0 \\
\hline Total & 90 & 10 & 10.0 \\
\hline
\end{tabular}

Table 6 shows overall mortality was $10 \%$ in this study. Highest mortality was present in the tubercular pathology (46.6\%). Mortality in enteric perforation was $7.14 \%$

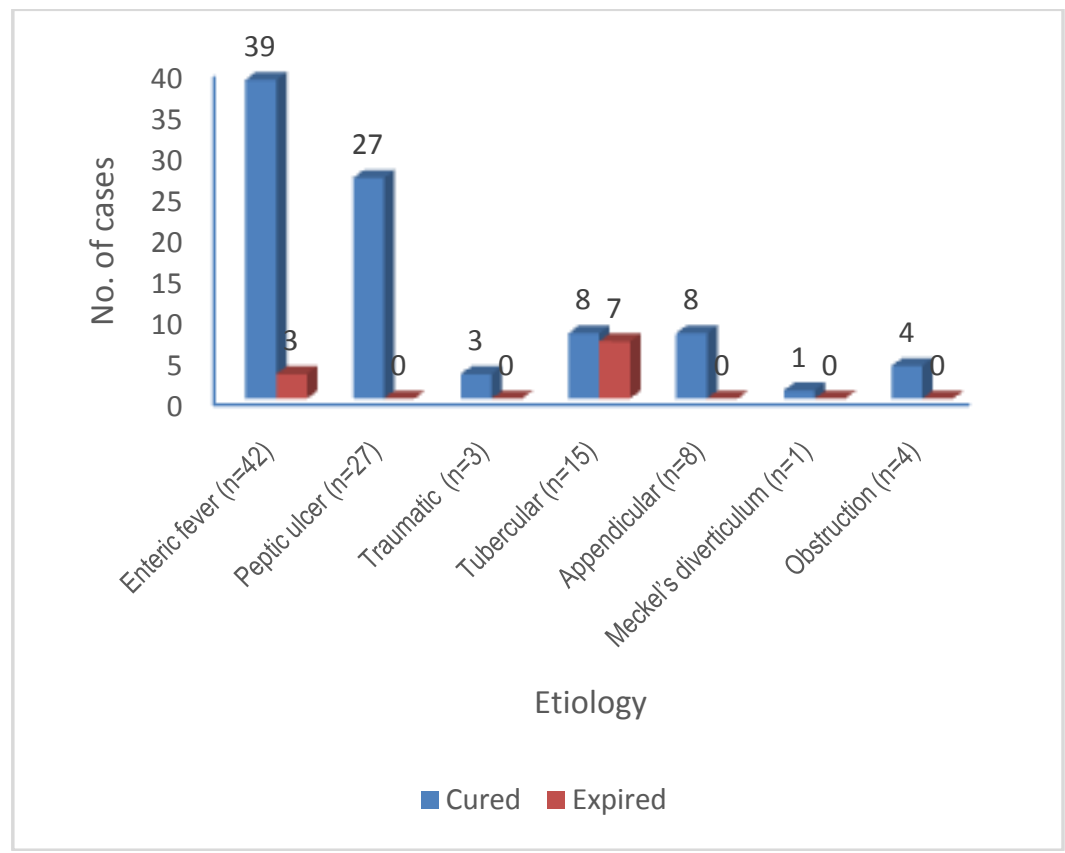

\section{Discussion}

Perforation peritonitis is a frequently encountered surgical emergency in any hospital with high morbidity and mortality, which continues to be a matter of great concern to the surgeons, particularly in a tropical country like India.

At the time of presentation, general condition of the patient is usually very much deteriorated and his/her outlook is very grim, he/she is in great agony and deserves skillful emergency surgical management.

The present study was undertaken to study the etiology, clinical profile, aids to diagnosis and management of perforation peritonitis. A total of 100 cases of perforation peritonitis coming to the surgical emergency and OPD of the Guru NanakDev Hospital/ Govt. Medical College Amritsar were studied.

Out of 100 cases which were studied, the most common etiology of perforation peritonitis was due to enteric fever (42 cases), the $2^{\text {nd }}$ most common etiology was due to peptic ulcer perforations (27 cases), other cases were due to tuberculosis (15 cases), appendicular perforations ( 8 cases), perforation due to intestinal obstruction (4 cases), blunt trauma ( 3 cases) and Meckel's diverticular perforation (1 case).

This study matches with the study of Khanna AK et al ${ }^{6}$ (108 out of 204 cases were of typhoid Etiology), but differs with several other previous studies (Jhobta et $\mathrm{al}^{2}$, Vagholkar $^{1}$, Gupta et al ${ }^{7}$, Sharma et $\mathrm{al}^{8}$ in their studies peptic perforations were the most common etiology and typhoid perforations were $2^{\text {nd }}$ most common etiology).

In this study the most common site of perforation was terminal ileum (upto $30 \mathrm{cms}$ proximal to ileocaecal junction) present in 55 cases (55\%), next most common site was stomach (20 cases), other sites were $1^{\text {st }}$ part of duodenum ( 7 cases), appendix ( 8 cases), caecum ( 5 cases), jejunum ( 2 cases), Meckel's diverticulum ( 1 case) and in 2 cases site of perforation was not identified due to severe adhesions between the gut loops.

In present study, the average time of presentation to the hospital with signs/symptoms of perforation peritonitis was 2.98 days (71.5 hours). This delay in presentation to the hospital was also noted in the previous 
studies by Jhobtaet $\mathrm{al}^{2}$ and $\mathrm{Kim}$ et $\mathrm{al}^{9}$ (more than $50 \%$ cases were explored more than 24 hours after their perforation occurred).

Acute abdominal pain (100\% cases) was the most common symptom of perforation peritonitis; other symptoms were abdominal distension (92\%), vomiting (88\%) constipation (78\%) and fever (77\%). All the patients $(100 \%)$ were presented to the hospital with signs of abdominal tenderness, rigidity and guarding, other signs were tachycardia (96\%), obliteration of liver dullness $(85 \%)$, shock $(32 \%)$ and absence of bowel sounds (80\%). X-ray chest PA view including both domes of diaphragm in standing position is a very useful investigation to diagnose the perforation of abdominal hollow viscus by detecting pneumoperitoneum. X-ray chest was done in 100 cases and pneumoperitoneum was detected in 93 X-rays. X-ray abdomen was done in 100 cases, pneumoperitoneum was detected in (85\%) and multiple air-fluid levels with or without pneumoperitoneum was the finding in (15\%) cases. USG abdomen was done in 100 cases. The most common ultrasonographic findings were free fluid in the peritoneal cavity $(95 \%)$ and dilated gut loops with sluggish or absent peristalsis (90\% cases). Pneumoperitoneum was detected in $50 \%$ cases only.

In the present study management was mainly surgical. Exploratory laparotomy was done in all cases after 3 to 4 hours of initial resuscitation.Pre-operative resuscitation included I.V fluids with electrolytes, Ryle's tube aspiration, Foley's catheterization, maintenance of input - output balance, blood transfusion, I.V antibiotics against gram positive, gram negative and anaerobes, monitoring of temperature, pulse and blood pressure regularly.Foul smelling seropurulent fluid with or without flakes in the peritoneal cavity was observed in 22 cases, foul smelling bilious fluid with or without flakes was observed in 27 cases, foul smelling fecal matter with or without flakes was observed in 46 cases, haemorrhagic fluid was observed in 5 cases.

The aims of surgical intervention are twofold: to drain the pus and bowel contents from peritoneal cavity and to prevent further contamination.Minimum required operative procedure was performed. In all the cases of peptic perforation, the edges were excised and margins freshened and perforation was closed in two layers by applying at least one layer with non-absorbable suture. Omental patch along with pedicle was also applied in all the cases. Meticulous peritoneal toileting was done with normal saline. ADK drain was inserted in pelvic cavity and paracolicgutter.In enteric perforation, simple closure of perforation was done with atraumatic needle in two layers/single layer. As the patients were poor surgical risk and they tolerate minimum anaesthesia, simple closure has the advantage of being quick and easy. An alternative procedure like resection and ileo-ileal anastomosis was also done in 3 cases where there were multiple perforations or distal gut was not healthy.

In 9 cases of enteric perforation where the gut was not healthy enough or with multiple perforations or there was excessive soiling, exteriorization of gut was done (ileostomy). Drainage of the peritoneal cavity is essential to drain out the residual pus and was done in all the cases.

In cases of tubercular perforations tubercles were present over the mesentery, omentum and serosal surface of the gut. Caseous material was also noted in the peritoneal cavity. Adhesions between gut loops were also present. In 4 cases stricture distal to the perforation was present. In most of the tubercular perforations resection and anastomosis (6 cases) or ileostomy (6 cases) was done.Majority of the appendicular perforations were treated by appendicectomy ( 7 out of 8 cases), 1 case had to undergo resection and ileoascending anastomosis because of perforation at the base of appendix and severe inflammation of the caecum. 2 of the 4 cases of obstruction underwent resection and anastomosis. In other 2 cases of obstruction where site of perforation could not be found, ileostomy had to be done. 2 out of 3 cases of traumatic perforations were treated by primary closure of the perforation. In one case resection and anastomosis was required due to multiple perforations.Meckel's diverticular perforation required resection and anastomosis.

Postoperatively patients were given I/V fluids, ryle's tube aspiration, blood transfusion, antibiotics such as $3^{\text {rd }}$ generation cephalosporin and metronidazole for anaerobic organisms. This treatment is recommended by most of the previous authors. Anti-tubercular drugs given to all patients with tuberculosis. In this study pain was the most common postoperative complication which was presented in $100 \%$ of the patients, $2^{\text {nd }}$ most common postoperative complication was fever, which was presented in $94 \%$ of the patients. Other postoperative complications were paralytic ileus $(85 \%)$, wound infection/dehiscence $(70 \%)$, anaemia/hypoproteinemia $(30 \%)$, chest infections (25\%), burst abdomen (12\%), anastomotic leaks (8\%), superficial/deep abscess (5\%), intestinal obstruction (4\%) and incisional hernia (2\%).In the study of Agrawal et al ${ }^{10}$, incidence of major complications was $25 \%$ (burst $11 \%$, leak 5\%, intra-abdominal abscess $5 \%$ and multi organ failure $6.5 \%$ ). In the study of Jain et $\mathrm{al}^{4}$, superficial wound infection $(46.8 \%)$ was the most frequent postoperative complication followed by wound dehiscence $(31.3 \%)$ and entero-cutaneous fistula/leak $(11.5 \%)$.

During the follow up period of 3 months, out of 35 cases of wound dehiscence, in 15 cases $(42.86 \%)$ resuturing of the wound was done after the wound was red and healthy. Rest 20 cases $(57.14 \%)$ were healed by secondary intension by local wound management (dressing). All the 12 cases of burst abdomen in which defect in the rectus sheath was present, resuturing of the defect was done. Out of 17 cases of ileostomy, ileostomy closure was done in 13 cases after primary pathology was cured and gut was healthy. 4 cases expired postoperatively 2 out of 8 cases of anastomosis leak required resection and anastomosis, rest were treated 
conservatively by bowel rest, IV antibiotics, IV fluids. Out of 4 cases of obstruction encountered during followed up, 2 cases required exploratory laparotomy with adhesiolysis, 2 cases were managed conservatively by RT aspiration, bowel rest, IV antibiotics, IV fluids.2 cases of incisional hernia developed at the scar site, required mesh repair of the defect. The overall mortality in the present study is $10 \%$. The causes of mortality in the present series are very poor general condition of the patient at the time of admission, anemia, toxemia, dehydration and patients reported later after the perforation. Most of the cases ( 7 of 15) were of tubercular perforations.

\section{Conclusion}

Perforation peritonitis causes considerable morbidity and mortality as patients usually present late to the hospital for treatment and their general condition isdeteriorated.Followingare the main features and conclusions of this study:

1. Enteric perforation is the most common cause of perforation peritonitis (42\%), followed by peptic ulcer perforation $(27 \%)$.

2. The most common site of perforation is terminal ileum (55\%), followed by stomach (20\%) and appendix $(8 \%)$.

3. Diagnosis is made by clinical examination and confirmed by the detection of pneumoperitoneum on X-ray chest/abdomen, ultrasonography of the abdomen and often by the four quadrant aspiration.

4. Pain abdomen (100\%) is the most common symptom of perforation peritonitis, other symptoms are distension (92\%), vomiting (88\%), constipation (78\%) and fever (77\%).

5. Abdominal tenderness, muscle rigidity and guarding are the most common $(100 \%)$ signs of perforation peritonitis

6. Tachycardia (96\%), obliteration of liver dullness (85\%), absent bowel sounds (80\%) and shock (32\%) are the other signs of perforation peritonitis

7. Exploratory laparotomy and closure of perforation is the commonest surgical procedure done in ileal and jejunal perforations.

8. Omental patching is the commonest surgical procedure done in peptic ulcer perforations.

9. Resection and anastomosis and Ileostomy are the surgical procedures done in case of multiple ileal perforations and/or in case of unhealthy, oedematous bowel wall or perforation with tubercular pathology.

10. Pain is the most common early postoperative complication (100\%), followed by fever (94\%), paralytic ileus $(85 \%)$, wound infection / dehiscence $(70 \%)$, anaemia/ hypoprotenemia (30\%), chest infection (25\%), burst abdomen (12\%), anastomotic leak (8\%), superficial/deep abscess (5\%), intestinal obstruction (4\%) and incisional hernia $(2 \%)$.

11. Incidence of resurgery in patients of perforation peritonitis is $46 \%$ with most common surgical procedure performed during resurgery is resuturing of the laparotomy wound $(27 \%)$, either due to wound dehiscence (15\%) or due to burst abdomen (12\%), followed by ileostomy closure (13\%), resection and anastomosis (2\%), exploratory laparotomy with adhesiolysis $(2 \%)$ and mesh repair of incisional hernia (2\%).

12. Overall mortality in perforation peritonitis is $10 \%$ with highest mortality in tubercular perforations $(46.6 \%)$.

\section{References}

[1]. Vagholkar KR. Therapeutic options in perforation peritonitis. Hospital Today 2011; 6(5):277-81

[2]. Jhobta RJ, Attri AK, Kaushik R, Rajeev Sharma and AupamJhobta. Spectrum of perforation peritonitis in India-review of 504 consecutive cases. World journal of Emergency Surgery 2006, 1:26

[3]. Chouhan MK, Pande SK. Typhoid enteric perforaton. Br J Surg 1982; 69:173-5.

[4]. Jain BK, Arora H, Srivastava UK, Mohanty D, Garg PK. Insight into the management of non-traumatic perforation of the small intestine.

J Infect DevCtries 2010;4(10):650-54.

[5]. Patil PV, Kamat MM, Milan MH. Spectrum of perforative peritonitis-a prospective study of 150 cases. Bombay Hosp J. 2012;54:38-50.

[6]. Khanna AK, Mishra MK. Typhoid perforation of the gut. Postgraduate Medical Journal 1984;60:523.

[7]. Gupta S, Kaushik R. Peritonitis -the Eastern experience. World J EmerSurg 2006; 1:13.

[8]. Sharma L, Gupta S, Soin AS, Sikora S, Kapoor V. Generalized peritonitis in India-the tropical spectrum. Jpn J Surg 1991; 21(3): $272-7$.

[9]. Kim JP, Oh SK, Jarrett F. Management of ileal perforation due to typhoid fever. Ann Surg 1975;181:88-91

[10]. Agarwal N, Saha S, Srivastava A, Chumber S, Dhar A, Garg S. Peritonitis: 10years' experience in a single surgical unit. Tropical Gastro 2008,pp. 1-6. 